\title{
Parametric test for the preliminary design of suspension bridges
}

\author{
M. R. T. Arruda ${ }^{1}$ (i) J. P. M. Serafim ${ }^{2}$
}

Received: 28 September 2016/Accepted: 29 April 2017/Published online: 9 May 2017

(c) The Author(s) 2017. This article is an open access publication

\begin{abstract}
The preliminary design of suspension bridges is a very important step in the design of a structure, since this stage is the one that will lead to an efficient and economic structure. The models that are used nowadays are complex and sometimes hard to apply, leading to a lack of comprehension from the designing team. This work proposes a new simplified method for the preliminary design of cable suspension bridges that relate the stiffness of the deck truss with the stiffness of the cable, in which stresses are calculated. This relation is intended to know how much of the live load is absorbed by each of these elements and finally obtaining the pre-design values of each substructure. First simple parametric tests are executed using the proposed method and finite element method with geometrical nonlinear analysis, in order to study its accuracy. Finally, a real case study is analysed using a known Portuguese suspension bridge, in which the proposed method is applied and compared with numerical solutions.
\end{abstract}

Keywords Suspension bridges - Preliminary design . Deflection theory of the suspension bridge - Stiffness distribution · Parametric analysis · Uniform and point loads

M. R. T. Arruda

mario.rui.arruda@tecnico.ulisboa.pt

J. P. M. Serafim

j.serafim@campus.fct.unl.pt

1 CEris, ICIST, Departamento de Engenharia Civil, Arquitetura e Georrecursos, Instituto Superior Técnico, Universidade de Lisboa, Av. Rovisco Pais, 1049-001 Lisbon, Portugal

2 Departamento de Engenharia Civil, Faculdade de Ciências e Tecnologia, Universidade Nova de Lisboa, 2829-516 Caparica, Portugal

\section{Introduction and historical remarks}

Cable supported bridges are one of the oldest structures in history, there are few structures that are universally appealing as these, the origin of the concept of bridging large spans with cables, exerting their strength in tension, is lost in antiquity and undoubtedly dates back to a time before recorded history. These structures arise so primitive humans that wanted to cross natural obstructions, observed a spider spinning a web or monkeys traveling along hanging vines (Brockenbrough and Merritt 1999). Nevertheless, it was in the 18th century that there was a major development in these structures, the crescent development of the structures started with the production of iron on a full scale (Chen and Duan 2014). Since the materials and systems used in these structures were fragile, the bridges were considered temporary. Because of that, there were a crescent search in new materials and technology's that helped to increase the life-time of these structures. In 1823, Marc Seguin designed the first permanent cable suspension bridge, the Saint Antoine bridge in Genebra. He and his five brothers started the design of several bridges and built more than a thousand in 20 years (Gimsing and Georgakis 2011). These structures gave the experience and the knowledge needed to rise bridges with bigger spans and sizes. The engineers in that time did not rely on scientific methods but on the empirical knowledge obtained by the experience. This fact and the insufficient variety of materials leaded to the decrease of interest in the implementation of these structures from the nineteenth to twentieth centuries. Therefore, it is possible to say that the failure in understanding the behaviour of the stayed systems and the lack of methods for controlling the equilibrium and compatibility of the various highly indeterminate structural components, appear to have been the major drawback to 
further development of the concept (Drewry 1832). There was then needed to rise a new generation of engineers that could get through these obstacles. The Rankine theories based in linear elastic models, led to new design solutions. These theories leaded to new methods of design that could approximate the values obtained by manual means (Gimsing and Georgakis 2011). From this time on, the design was not solely based on the experience but also in the scientific methods that could lead to better solutions. It was after the Second World War that the suspension bridges had their major period in Europe, the need of access of a large number of cities leaded to the discovery of several new technologies and methods that led to a better construction.

The known analytical methods for studying suspension bridges (Gimsing and Georgakis 2011; Timoshenko and Young 1965) are extremely heavy to be applied in the preliminary design phase since they rely on iterative procedures. Some simple methods based on "static equilibrium" theories also exist (Irvine 1981), but these are extremely conservative which lead to non-economic solutions (Tadaki 2010).

The authors proposed a different method based on a simple proportional analysis between the girder and the cable stiffness (Serafim 2014). The main advantaged is its simplicity, since all relations are based on direct linear analysis, without any iterative process. This method is later on compared with a numerical analysis using finite element models (Belytschko and Fish 2007), using geometrical non-linear analysis (Crisfield 1991, 1997).

\section{Previous work}

The theory of the displacements of a suspension bridge was first formulated by Melan in 1888 (Melan 1913). This was the first method to be used because it is extremely efficient when it's used in the analysis of a bridge with a flexible deck girder. There are several ways to study the forces currently on a structure like this, which have been applied over the years in the design of suspension bridges.

The first one is the "static analysis" (Gimsing and Georgakis 2011) of a suspension bridge that neglects the deflection caused by the geometry of the structure and the equilibrium equations are linear. Nevertheless, the neglection of the deflections can lead to inaccurate and non-economic results when trying to obtain the stress values. This method was used to study the structures that had a small span or that the deflections due to the live loads were relatively small. The second one is the theory that permits the analysis of deck girders of brides, this theory is called "theory of displacements" (Von-Karman and Biot 1940) of suspension bridges. This theory is used when the stiffness of the girder is high and the displacements that were caused by the live loads are considered small. This theory assumes that the configuration that the cable assumes is a parabola and it is possible to obtain the equation that gives the displacement of the structure in any point.

There are also several graphical methods (abacus) that can be used to estimate the values of the preliminary design forces of suspension brides. The first is the preliminary design by Steinman-Baker (Gimsing and Georgakis 2011) that is used for bridges with a small span and stiffed girders (so the displacements are small). This method is simple to be used for preliminary analysis and it uses a SteinmanBaker coefficient to extrapolate the percentage of shear force and moment that is present in the mid span and the side span.

The coefficient is given by (1):

$S=\frac{1}{L_{\text {span }}} \sqrt{\frac{\mathrm{EI}}{H_{\mathrm{dl}}}}$,

where EI is the stiffness of the girder and $H_{\mathrm{dl}}$ is the horizontal force of the cable due to the dead load. This coefficient is latter used in the Steinman-Baker charts Fig. 1 to obtain the percentage of the Shear Force and the Moment present in the girder.

The second process that is used for the preliminary analysis of a suspension bridge is the Hardesty-Wessman process (Brockenbrough and Merritt 1999). This process is based in the distortion of the structure and gives more realistic values of the forces. It correlates the deflection in percentage of the cable sag with the relation of the live loads and the dead loads to obtain the parameters that are used in several formulas (Fig. 2).

\section{Proposed method}

The preliminary design of cable suspension bridges can be obtained from a numerous different ways and methods, from the deflection theory of the suspension bridge (Timoshenko and Young 1965), to the computational models that can be obtained with the proper software (Wilson 2002). All of these methods can be very exhausting and sometimes require large amounts of computational time. These problems lead to the need of a new simplified method that can unite the precision of the obtained results with a less amount of time that takes to obtain them.

The forces that this method manages to calculate is the bending moment $(M)$ at mid span in the deck and the horizontal cable tension $(H)$ on top of the towers/pylons.

This method is applied for two load situations:

- Uniform load-distributed at the mid span

- Point load—applied at the centre of the mid span. 
(a)

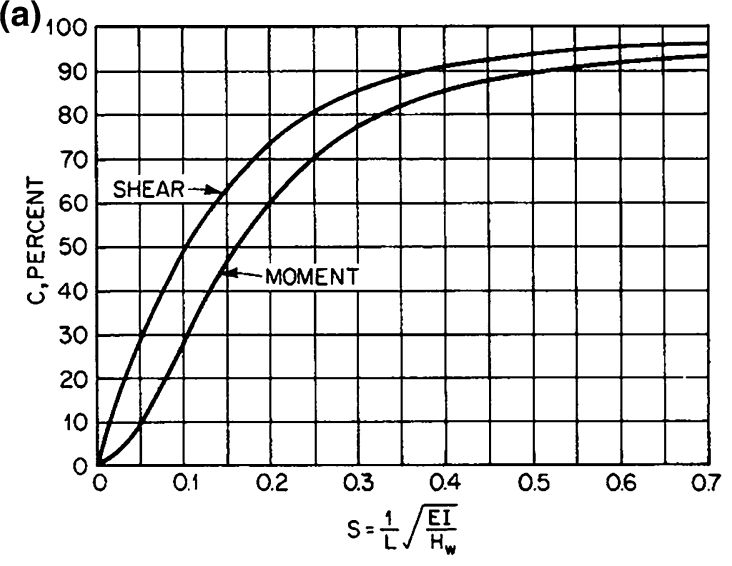

(b)

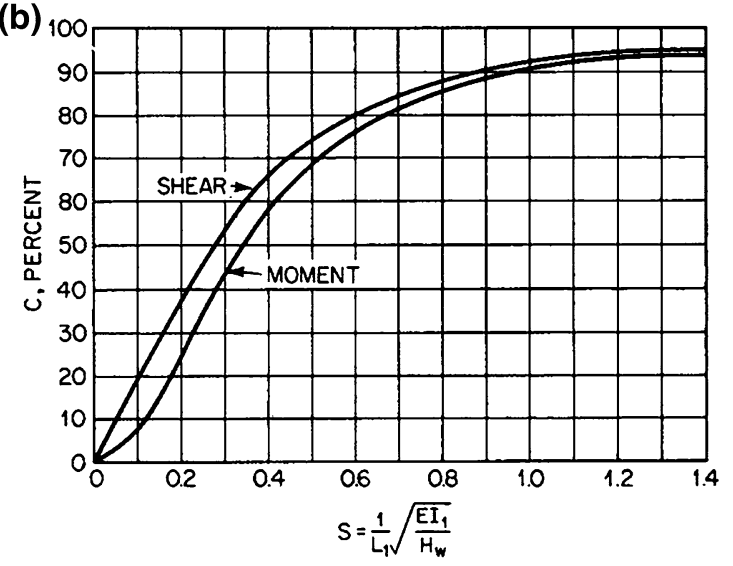

Fig. 1 Steinman-Baker charts. a Mid span, b side span (Gimsing and Georgakis 2011)

(a)

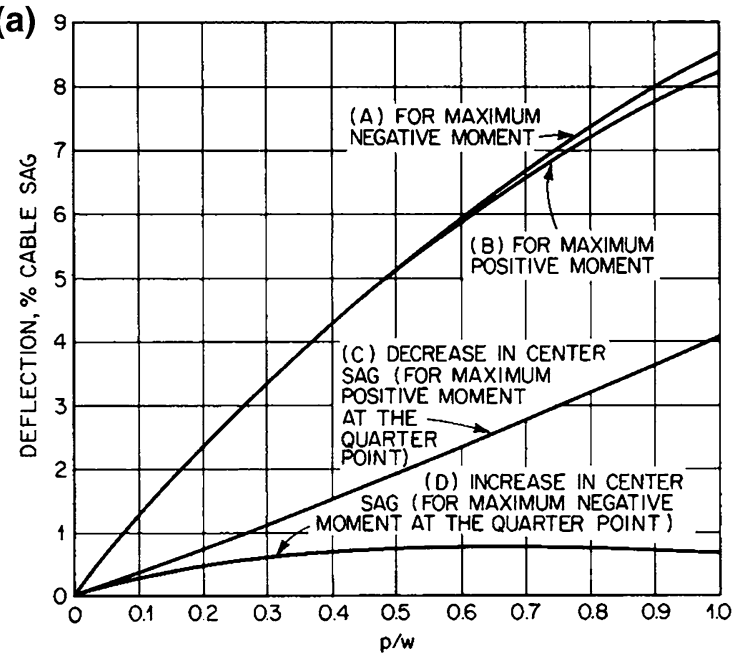

(b)

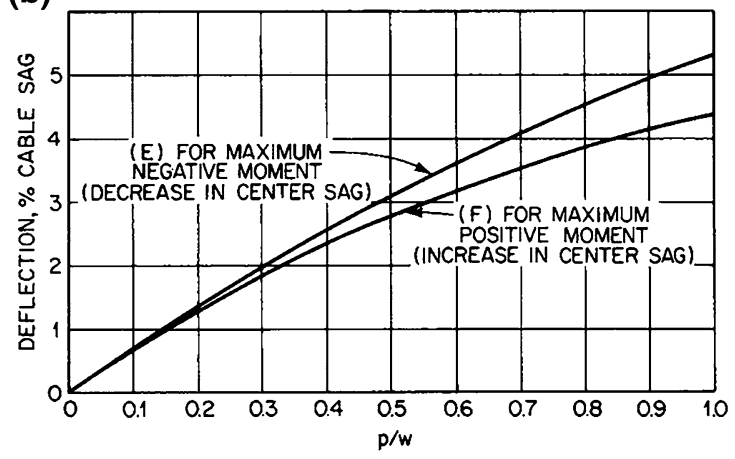

Fig. 2 Charts that lead to the displacements of a unstiffened cable due to a partial load. a Maximum displacement at $1 / 4$ of span. b Displacement at mid span (Gimsing and Georgakis 2011)

The loads that are going to be introduced are the live loads that can be produced by traffic, which depend on the country structural codes. The dead load is not applied, since during the construction phase of the suspension bridged it is all transferred to the cable (Holger 2013). Although the method is precise, it relays on some simplifications such as: it is admitted a parabolic cable shape; the hanger tendons are rigid and continuous; the load that is transferred to the cross section of the deck girder is uniform; the effect of the shorting due to the compression of the deck is negligible; it does not take into account the horizontal and vertical flexibility of the towers; for the deck girder only the bending flexibility is taken into consideration; the cable is already deformed due to the self-weight of the cable and girder [this last hypothesis is very common in other simplified methods (Timoshenko and Young 1965; Von-Karman and Biot 1940), since it happens due to the construction phase (Parke and Hewson 2000; West and Robinson 1967)].

This method is applied to the mid span of a cable suspension bridge. The model of the suspension bridge is going to be the one that is represented in Fig. 3, in this model, both ends of the cable and the girder are simply supported (pinned) and the hangers are the only physical connection that are between both structures.

This method requires that the hangers are rigid and without any deformation, and two geometric parameters and two stiffness that are require to be considered; the length of the mid span $\left(L_{\mathrm{span}}\right)$; the sag of the cable $\left(f_{\mathrm{w}}\right)$; the cable area $\left(A_{\mathrm{c}}\right)$; and the deck girder inertia $\left(I_{\mathrm{g}}\right)$.

The cable area is the total cross section, if the structure has two or more cables this area is the sum of all crosssection areas, the girder inertia is considered to be constant trough all span. 
Fig. 3 Model of the cable suspension bridge studied in this work

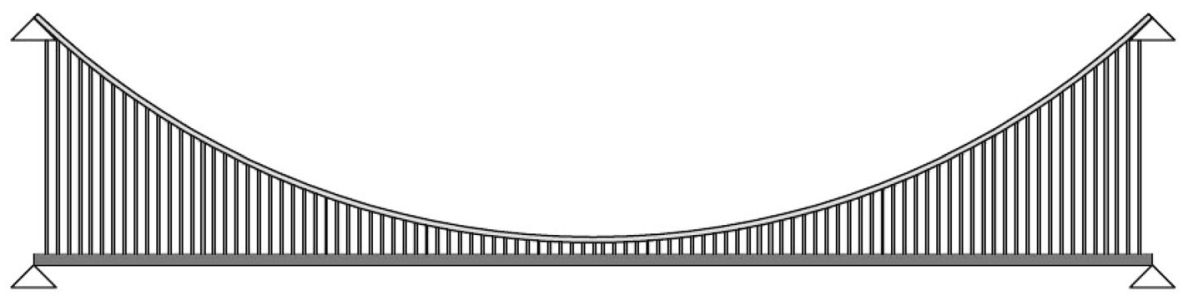

Since there is two types load cases that can be used, this method is divided into two parts. The first is going to study the uniform live load and the second the point load. Both parts are going to give the approximate values of the forces that are going to be studied but each one has a different approach.

\section{Uniform load}

To obtain the forces for the uniform load it is required to understand the deflection theory of suspension bridges (Jennings 1987; Von-Karman and Biot 1940). This theory implies that the displacements that occur due to the live load, introduce equal displacements, both in the cable and the girder (Fig. 4), [recalling that the deformation of the structure due to the dead load is only transferred to the cable during the construction stage (West and Robinson 1967)]. This occurs due to the fact that the hangers cannot deform. This hypothesis is valid since it was observed "in situ" (Branco 1994) that these deformations remained relative small when compared with the cable and girder deformations.

In this case, as can be seen in the deflection theory of suspension bridges, the displacement that is introduced in the cable can be obtained (Timoshenko and Young 1965) using (2), if the deformation is small compared with the sag $f_{\mathrm{w}}$.

$\delta_{\mathrm{c}}^{\mathrm{p}}=\frac{\left(16 f_{\mathrm{w}}^{2}+3 L_{\mathrm{span}}^{2}\right) L_{\mathrm{span}}^{2} p}{128 A_{\mathrm{c}} E_{\mathrm{c}} f_{\mathrm{w}}^{2}}$.

This expression is of up most importance to comprehend the simplified method, in this equation, $\delta_{\mathrm{c}}^{\mathrm{p}}$ stands for the displacements produced by the uniform live load $p$, that is

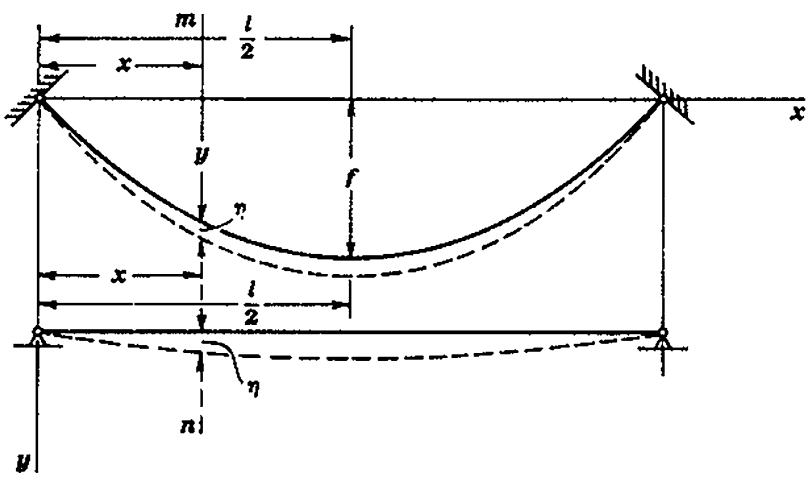

Fig. 4 Displacements of a suspension bridge due to a uniform live load applied on the length of the girder (Von-Karman and Biot 1940) applied in the span and $E_{\mathrm{c}}$ is the Young's module of the material of the cable.

The uniform load method can also be called the "ratio load method", since this procedure is based on the fact that the flexibility at mid span of the cable and the girder are the same $\left(\delta_{\text {cable }}^{\mathrm{p}}=\delta_{\text {girder }}^{\mathrm{p}}\right)$. With this hypothesis it can be considered that the structure (as can be seen on Fig. 3), can be divided into two sub structures, a simply supported girder and a simply suspension cable Fig. 5 .

It is implied that both structures are loaded with a unique load that combined is equal to the total load introduced in the structure (3). This total load that is introduced in the structure, has to be in $\mathrm{kN} / \mathrm{m}$ so can be used in a 2D model, to achieve this load, the uniform load in $\mathrm{kN} / \mathrm{m}^{2}$ has to be multiplied by the deck's width.

$p_{\text {total }}=p_{\text {cable }}+p_{\text {girder }}$.

In this case, each structure is going to have a unique stiffness, that combined can be called the total stiffness of the cable suspension bridge. To obtain each sub structure stiffness a direct approach (Martha 2009) is implemented using a unitary load, and calculating its respective displacement. In this case the displacements are equal to the flexibility of the structure, and when inverting these displacements the stiffness of each element is obtain. For a simply supported girder the equation that leads to the flexibility (Ghali and Nevillle 1997) of the structure is represented next (4):

$\delta_{\mathrm{g}}^{\mathrm{p}}=\frac{5}{384} \times \frac{p L_{\mathrm{span}}^{4}}{E_{\mathrm{g}} I_{\mathrm{g}}}$,

where $E_{\mathrm{g}}$ is the Young's module of the material constituent of the girder and $\delta_{\mathrm{g}}^{\mathrm{p}}$ is the displacement that the uniform load produces on the structure. Replacing $p$ in (2) and (3) for a unit uniform load $\bar{p}=1.0$ it is obtained the Eqs. (5) and (6) that lead to the flexibility of the structures and consequently to the stiffness of the sub elements.

$K_{\mathrm{c}}^{\mathrm{p}}=\frac{1}{\delta_{\mathrm{c}}^{\mathrm{p}}}$,

$K_{\mathrm{g}}^{\mathrm{p}}=\frac{1}{\delta_{\mathrm{g}}^{\mathrm{p}}}$.

Having both stiffness of the elements, it is important to obtain the load that each element is going to absorb (Inglis 


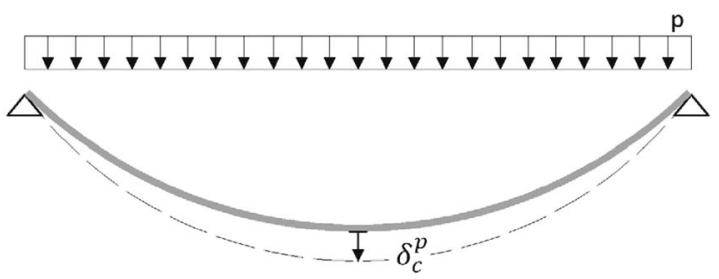

Fig. 5 Sub structures of a cable suspension bridge

1963). This is succeeded by using a ratio formula to obtain the separate loads in the cable (7) and girder (8).

$p_{\text {cable }}=\frac{K_{\mathrm{c}}^{\mathrm{p}} \times p_{\text {total }}}{K_{\mathrm{c}}^{\mathrm{p}}+K_{\mathrm{g}}^{\mathrm{p}}}$,

$p_{\text {girder }}=\frac{K_{\mathrm{g}}^{\mathrm{p}} \times p_{\text {total }}}{K_{\mathrm{c}}^{\mathrm{p}}+K_{\mathrm{g}}^{\mathrm{p}}}$.

After obtaining the loads that each element have, it is necessary to obtain the design forces of the structure. These forces are the horizontal cable tension and the bending moment at the centre of the mid span. These forces can be obtained by using the static equilibrium (Irvine 1981) and the formulas are given by (9) and (10):

$H=\frac{p_{\text {cable }} L_{\mathrm{span}}^{2}}{8 f_{\mathrm{w}}}$,

$M=\frac{p_{\text {girder }} L_{\text {span }}^{2}}{8}$.

Having both forces, the preliminary design of the cable and deck girder can be achieved. It is important to point out that if the cable presents an almost rigid behaviour, the proposed method converges for the exact solution. Later on demonstrated in Fig. 11.

\section{Point load}

To obtain the bending moment at the span and the cable tension from a load applied at the centre of the structure it is necessary to understand the theory of beams on elastic foundation (Hetenyi 1971). Using this theory the bending moment can be achieved applying the next formula (11):

$M_{\mathrm{c}}=\frac{P}{4 \beta} \frac{\sinh \beta L_{\mathrm{span}}+\sin \beta L_{\mathrm{span}}}{\cosh \beta L_{\mathrm{span}}+\cos \beta L_{\mathrm{span}}}$,

where $M_{\mathrm{c}}$ is the bending moment at the centre of the span, $P$ is the point load that is applied at the centre of the structure, $L_{\mathrm{span}}$ is the total length of the span and $\beta$ is a system characteristic coefficient that correlates the stiffness of the foundation with the stiffness of the beam (Bowles 1995). This parameter can be obtained by using the next expression (12):
$\beta=\sqrt[4]{\frac{K_{\text {foundation }}}{4 E I_{z}}}$,

where $K_{\text {foundation }}$ is the stiffness of the foundation, $E$ is the Young's module of the beam and $I_{z}$ is the beams inertia in the $z$ axis. To obtain the systems characteristic coefficient is necessary to assume a $K_{\text {foundation }}$ so that the bending moment can be obtained.

Since the hangers of the structure are considered to be rigid, it can be assumed that the equivalent foundation stiffness is the stiffness of the cable.

Of course that this is an ill-mannered simplification that is needed to be used so the $\beta$ can be achieved. The stiffness of the cable can be obtained by considering two cases.

- The stiffness of the cable is obtained by a unitary point load.

- The stiffness of the cable is obtained by a uniform load.

It was concluded that the best results obtained where the ones where the stiffness of the cable is obtained by a unitary point load. So, the stiffness of the cable can be obtained by considering the next model (Fig. 6).

Using the next formula (Ghali and Nevillle 1997) the stiffness of the cable can be obtained (13):

$K_{\mathrm{c}}=\frac{2 E_{\mathrm{c}} A_{\mathrm{c}}}{L^{\prime}} \cos ^{2} \alpha$,

where $K_{\mathrm{c}}$ is the stiffness of the cable in the point where the load is applied, $A_{\mathrm{c}}$ is the area of the cross section of the cable and $L^{\prime}$ is the distance from point A to B. This stiffness cannot be considered the $K_{\text {foundation }}$ yet, since this is the stiffness of the point where the point load is applied. Then it is used another simplification, where the $K_{\mathrm{c}}$ is distributed along the size of the beam $L_{\text {span }}$. After these simplifications the bending moment at the mid span can be obtained.

To obtain the horizontal cable tension it is necessary to perform and equilibrium at mid span using the moment obtain from (11), using an equivalent simply supported beam, and calculating $P_{\text {beam }}=M_{\mathrm{c}} \times 4 / L_{\text {span }}$. Considering that $P_{\text {total }}=P_{\text {beam }}+P_{\text {cable }}$ it can be achieved the value of the point load applied on the beam and subsequently obtained the horizontal value of cable tension. 
Fig. 6 Deformed shape of the cable when a point load is applied at the centre

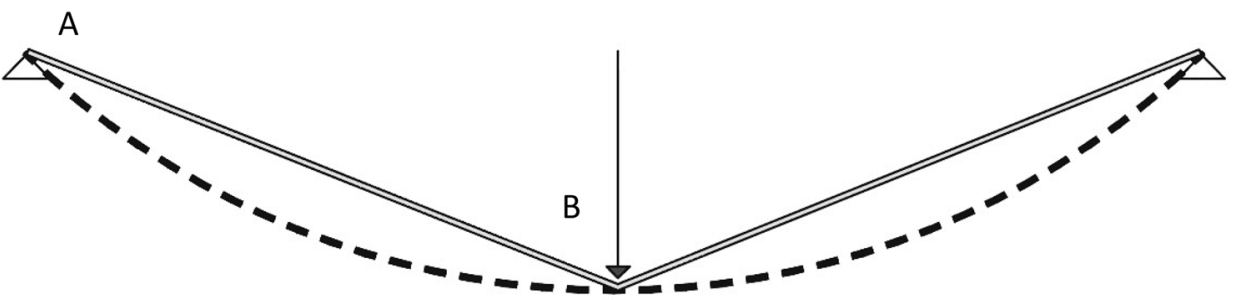

\section{Parametric study}

The parametric study that is used, considers the value of the loads present in the Portuguese structural safety code (RSA 1983) applied in the structure. These loads are considered the follow: uniform load of $q_{1}=40 \mathrm{kN} / \mathrm{m}$; and a point load of $q_{2}=500 \mathrm{kN}$. These are the loads that consider a situation where the bridge has heavy traffic.

The parametric study also changes the values of the length of the span $L_{\text {span }}$, the sag of the cable $f$, the cross section of the cable $a_{\mathrm{c}}$ and finally the beam inertia $I_{z}$. The control values that remain constant through the parametric analysis, are assumed according to known suspension bridges (Chen and Duan 2014), which are displayed in Table 1.

These parametric studies will compare the values obtained by the simplified method, and the ones obtained by the software (SAP 2000), in terms axial tension and bending moment. The static and kinematic boundaries of the numerical models, are the same as the ones represented in Fig. 3. Three type of finite elements were used: the 1st was the enhanced cable element for the cable (AhmadiKashani 1983; Tibert 1999); the 2nd was the frame element for the bridge girder; and the 3rd the kinematic rigid element for the hangers. It was limited the maximum size of all finite elements of $1.0 \mathrm{~m}$.

In the parametric analysis, only the relative error of the axial tension and bending moment are presented in the vertical axis, with a logarithmic scale, using as target the output from the finite element model:

Error $_{H} \%=\frac{\left|H_{\text {proposed }}-H_{\text {numerical }}\right|}{H_{\text {numerical }}} \times 100 \%$,
Error $_{M} \%=\frac{\left|M_{\text {proposed }}-M_{\text {numerical }}\right|}{M_{\text {numerical }}} \times 100 \%$.

It is important to point out that the proposed method uses a linearized approach, but the finite element method used in SAP2000 uses geometrical non-linear analysis. It is therefore expected some differences which are acceptable, since the outputs during the pre-design phase are not always the same as in the design phase (Menn 1990). In this case the proposed method is used in the pre-design phase and the SAP2000 in the final design phase.

\section{Span analysis}

In this analysis the span $L_{\text {span }}$ varies from 200 to $3000 \mathrm{~m}$, and the rest of the variables in Table 1 remain constant through the entire parametric study.

\section{Uniform load}

The results obtained with the proposed method are presented in the Fig. 7. These results show that the error of the cable tension, and the bending moment are low, for the current geometries for example in the cable tensions when using spans, from 500 to $2000 \mathrm{~m}$. These errors have values in between 0.24 and $6.17 \%$. Values which are acceptable for a preliminary design of a bridge. The results obtained for the bending moment are slightly higher, but they are acceptable for this design phase, in this case between 15 and $12 \%$. Below the span of $500 \mathrm{~m}$, the results tend to get poorest, because the cable is no longer near a parabolic approximation, therefore, the propose method starts to diverge from the numerical result. For span larger than 2000, the combined deformation of the cable and the girder start to be important, especially when writing the static equilibrium equations in the deformed shape for both cable and girder, therefore, it is expected that the proposed method presents coarse approaches.

\section{Point load}

The errors obtained by the point load, method are higher than the ones obtained by the uniform load as shown in Fig. 8. Nevertheless, these results are still in good agreement with the ones provided by SAP2000, for both cable tension and bending moment.
Table 1 Control values of the parametric test

\begin{tabular}{llll}
\hline Span, $L_{\text {span }}(\mathrm{m})$ & Sag, $f(\mathrm{~m})$ & Inertia, $I_{z}\left(\mathrm{~m}^{4}\right)$ & Cross section of the cable, $a_{\mathrm{c}}\left(\mathrm{m}^{2}\right)$ \\
\hline 1000 & 200 & 13.84 & 0.1963 \\
\hline
\end{tabular}


Fig. 7 Span analysis of the uniform load, cable tension and bending moment

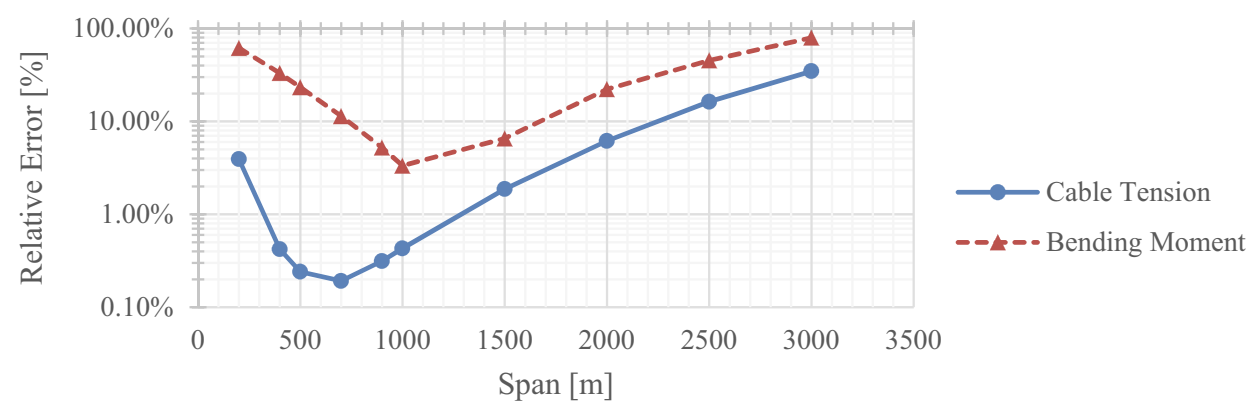

Fig. 8 Span analysis of the point load, cable tension and bending moment

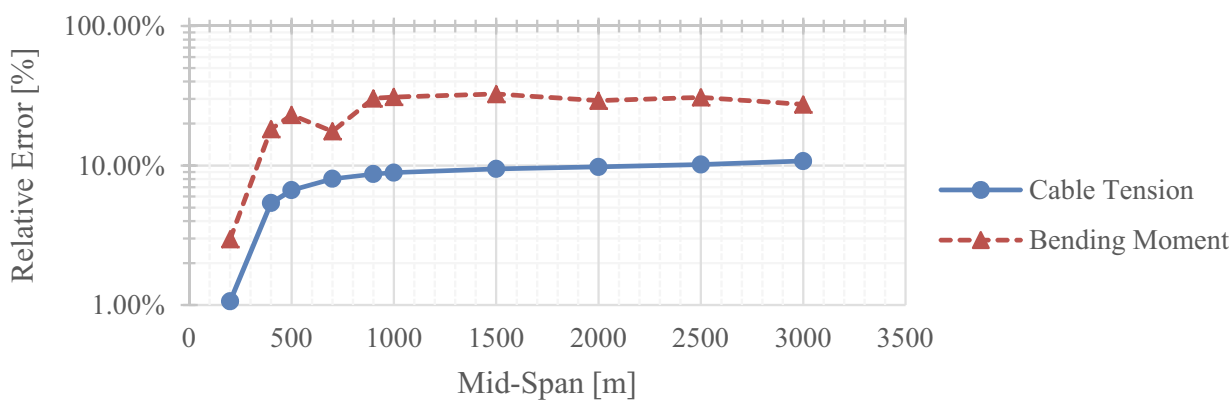

In this case the error for the cable tension is below 15\% and for the bending moment below 35\%. The difference between the uniform load, is the error is smaller below span of $500 \mathrm{~m}$. This is due to the fact that the proposed method admits a straight cable for the point load, which is near an exact value when the span of the suspension bridge is bellow $200 \mathrm{~m}$.

For spans bigger than $1000 \mathrm{~m}$, the error tends to stabilize, this is due to the fact that straight cable approximation follows the "secant" approach of the real cable deformation. In this case in terms of force resultant in mid span, the values are the same, only changing the axial stress direction, therefore maintaining a constant error trough the parametric analysis.

Although the errors are larger, in terms of pre-design phase it still can be concluded using the referrer parametric study, that the proposed method is adequate.

\section{Sag analysis}

In this analysis the sag $f$ varies from 50 to $500 \mathrm{~m}$, and the rest of the variables that were displayed in Table 1 remain constant through the entire parametric study.

\section{Uniform load}

The results from the sag analysis are displayed in Fig. 9, these have the same errors reported earlier in span analysis 4.1 , derived from a variation on the cable deformed shape (initially a parabolic one), when using low ratio of $f / L_{\text {span }}$. This is notable especially for sag below the $100 \mathrm{~m}$ and a span of $1000 \mathrm{~m}$, usually not the case in common cable suspension bridges (Leonhardt 1979).

The cable sag that varies between 100 and $200 \mathrm{~m}$ has low relative errors for the cable tension of 2.73 and $0.43 \%$ and for the bending moment of 5.63 and $8.16 \%$.

From the sag analysis, the results obtained are still acceptable to be used in a preliminary design when using current geometries of the structure, this shows that the method works well with general sag sizes.

\section{Point load}

Once again, the point load test shows higher errors, than the uniform load, nevertheless for general geometries the values obtained by the method are still good, for the preliminary analysis, when using cable tension with error below $15 \%$. But for the bending moment as shown in Fig. 10, the error can go far as $45 \%$, although it stables for the same reasons as the ones presented in Fig. 8 in "Point load". In any case for a value of sag between 100 and $200 \mathrm{~m}$, the value of the error is below $20 \%$ which are most of the cases in cable suspension bridges. Therefore, it is concluded once again, that for most of the cable suspension bridges geometries the proposed method is adequate for the pre-design phase.

\section{Cable cross-section analysis}

For this analysis the cross section $a_{\mathrm{c}}$ of the cable varies from 0.1 to $0.4 \mathrm{~m}^{2}$, and the rest of the variables that were displayed in Table 1 remain constant through the entire parametric study. 

uniform load, cable tension and bending moment
Fig. 9 Sag analysis of the

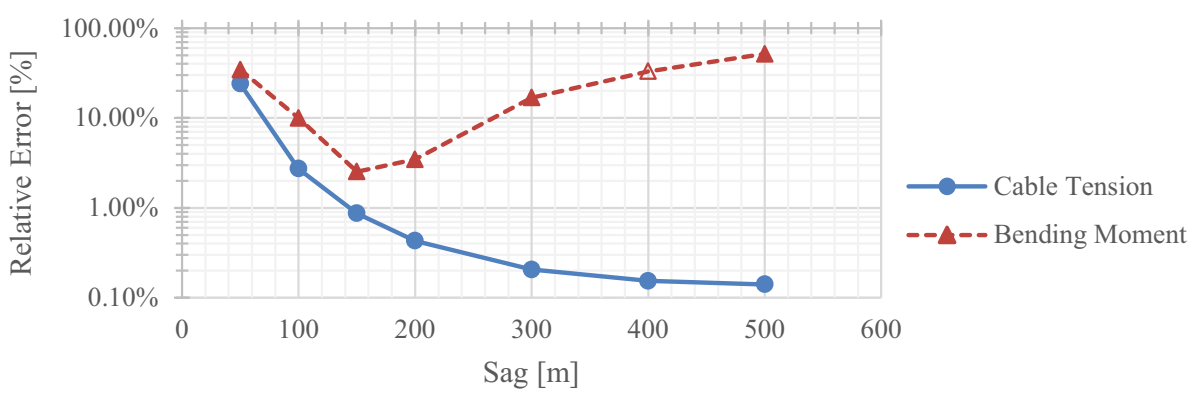

Fig. 10 Sag analysis of the point load, cable tension and bending moment

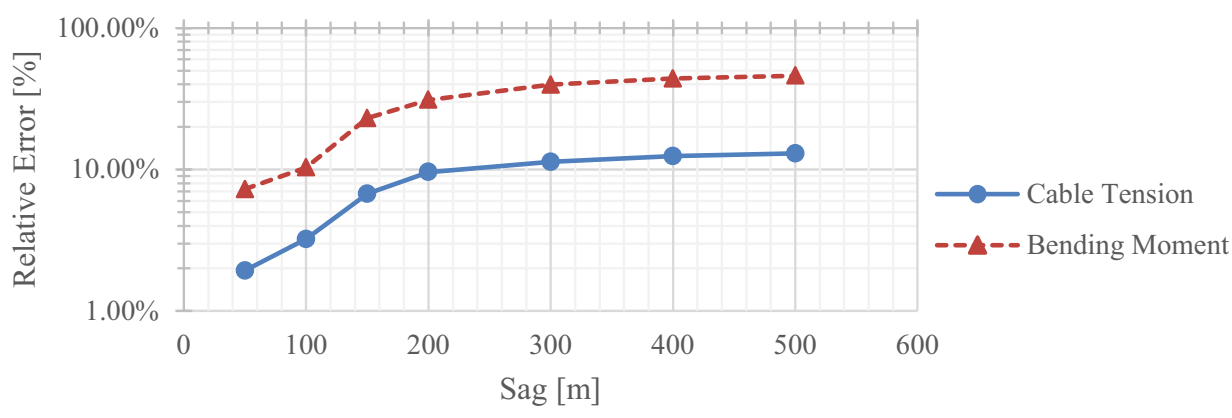

\section{Uniform load}

For both cable tension and bending moment the maximum error for cross-section area above $0.05 \mathrm{~m}^{2}$ is below $3.5 \%$. The errors obtained for both cable tension and bending moment are low and show the effectiveness of the simplified method.

When comparing the increasing of the cable cross section (and therefore its stiffness) the values of the error are consistently decreasing for the cable tension. This is due to the fact that if the cable increases its stiffness its deformation is smaller, maintaining its original deformed shape, in which the results of the proposed method (which admits the deformation of cable is negligible) are almost exact when compared with the real solution. This is closer to a rigid cable, in which the proposed method gives de exact solution (Fig. 11).

\section{Point load}

The errors obtained by the point load method are higher than the ones obtained by the uniform load as displayed in Fig. 12. Nevertheless, these results are still in good agreement for both cable tension and bending moment. In this case the error for the cable tension is below $14 \%$ and for the bending moment below $41 \%$. Also just like in "Span analysis" and "Sag analysis" the error tends to stabilize exactly for the same reasons explained before.

The difference between the uniform load, is the error is smaller below span of $500 \mathrm{~m}$. This is due to the fact that the proposed method admits a straight cable for the point load, which is near an exact value when the span of the suspension bridge is bellow $200 \mathrm{~m}$.

For spans bigger than $1000 \mathrm{~m}$ the error tends to stabilize, this is due to the fact that straight cable approximation follows the "secant" approach of the real cable deformation. In this case in terms of force resultant in mid span, the values are the same, only changing the axial stress direction, therefore maintaining a constant error trough the parametric analysis.

\section{Girder inertia analysis}

For this analysis the inertia $I_{z}$ of the deck girder varies from 0.01 to $28 \mathrm{~m}^{4}$, and the rest of the variables that were displayed in Table 1 remain constant through the entire parametric study.

\section{Uniform load}

The uniform load in the girder presents stable error values, this is due to the stiffness of the girder having a small contribution in the general structure stiffness. This leads to the conclusion that the girder stiffness is not very important in the parametric study of the simplified method since it has a very low value (Fig. 13).

\section{Point load}

Once more the values of the error presented by the point load are higher, but since the inertia of the girder (bending stiffness) is generally above $10 \mathrm{~m}^{4}$, it can be stated that the 
Fig. 11 Cable cross-section analysis of the uniform load, cable tension and bending moment

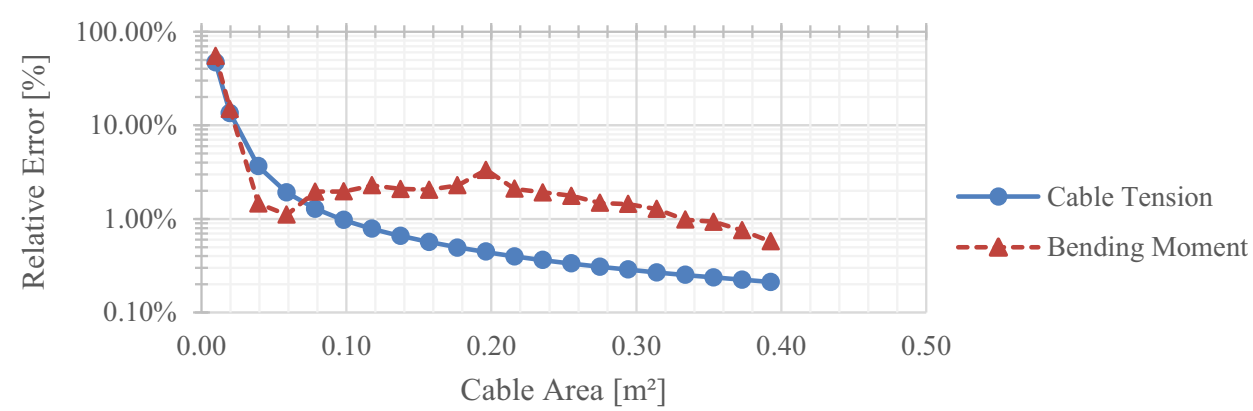

Fig. 12 Cable cross-section analysis of the point load, cable tension and bending moment
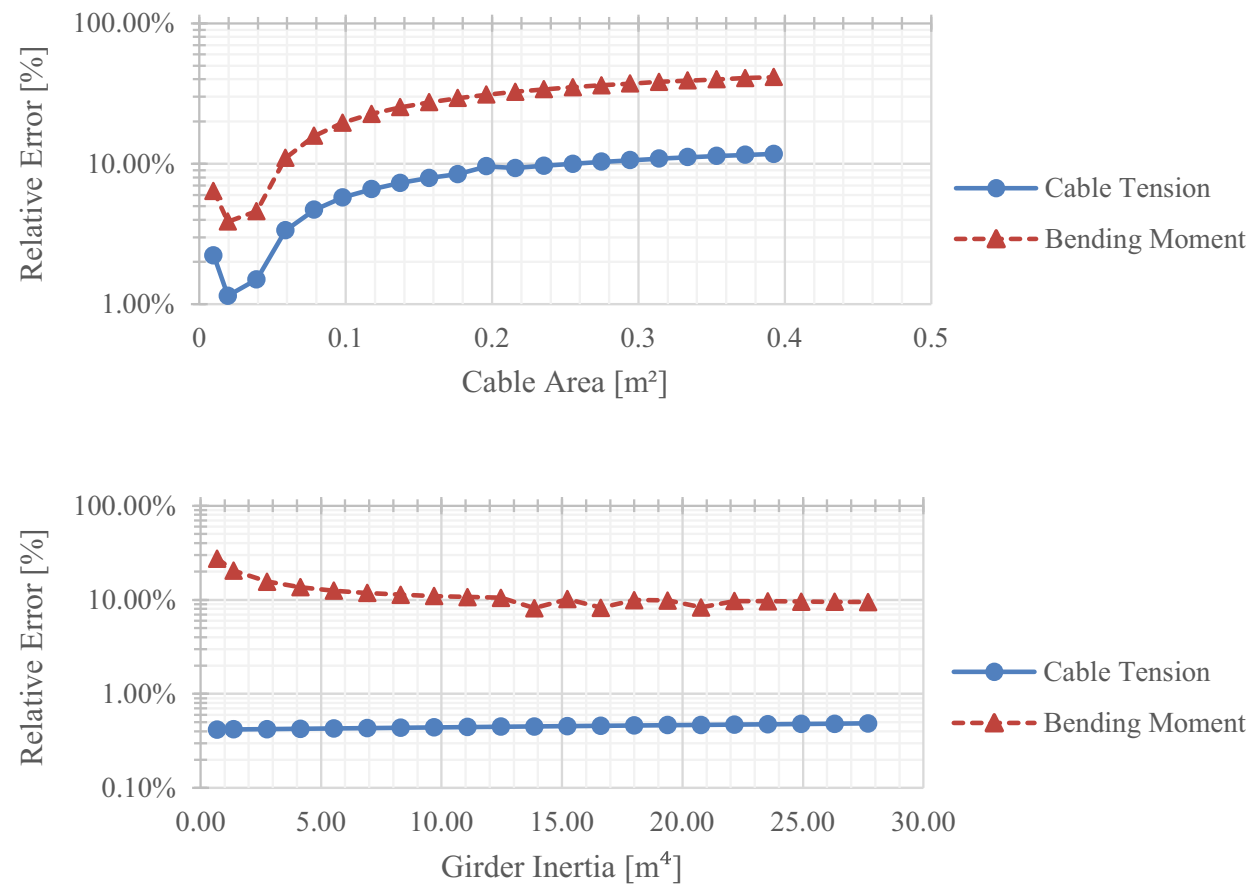

Fig. 13 Girder analysis of the uniform load, cable tension and bending moment error of the cable tension is below 10 and $40 \%$ for the bending moment. The proposed method in this case provides a good approximation for the cable tension, but a coarse estimation on the bending moment even in the predesign phase (Fig. 14).

\section{Application to real model (Tagus Bridge 25 de Abril)}

The simplified method is then applied to a real structure, the Tagus Bridge/25 de Abril (aka Salazar Bridge), a suspension bridge that was open to public in 1966 and was built by the United Steel International (Steinman 1960). This bridge was intended to have railway traffic, but the means that permitted such were only introduced later in 1992. When this alteration was made the girder was also expanded and since then the bridge permits car traffic and railway traffic simultaneous (Branco 1994; LUSOPONTE 2000) (Fig. 15).

\section{Materials and structural elements}

To proceed with the analysis of this structure it was required to know all the characteristics of the materials and structural elements. It was necessary to consult the original design report provided by Steinman (1960), which is presented in IST library. The materials were considered to be Steel and with a Young module of $195 \mathrm{GPa}$ and Poisson coefficient of 0.3 . From the initial report it was also possible to know the general geometry of the structure, presented in Table 2.

From the structural design project it was possible to see that each hanger presents a longitudinal spacing of $11 \mathrm{~m}$ from each other. The axial diameter of each of these hangers is admitted to be $64 \mathrm{~mm}$. The girder is a square truss, namely from the family of "Warren Truss with Verticals". The geometry of the sections that constitute the girder is the follow (Fig. 16).

The width of the girder was also obtained and it was considered to be $21 \mathrm{~m}$ long. Finally, the diameter of the 
Fig. 14 Girder analysis of the point load, cable tension and bending moment
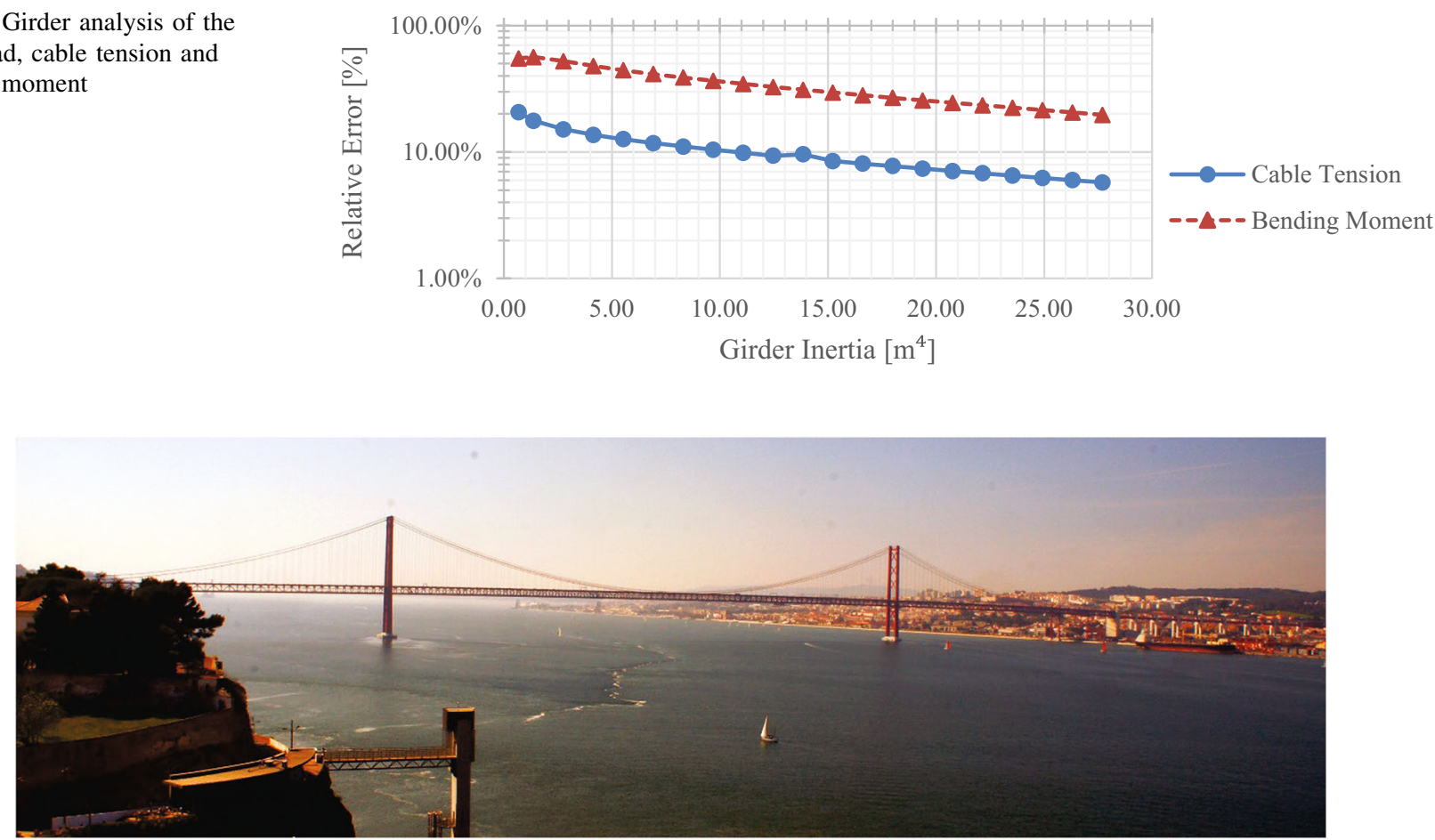

Fig. 15 Tagus Bridge 25 de Abril, view from the south side of the river

Table 2 General geometry of the structure

\begin{tabular}{lll}
\hline Sag $(\mathrm{m})$ & Midspan $(\mathrm{m})$ & Sidespan $(\mathrm{m})$ \\
\hline 103 & 1035 & 460 \\
\hline
\end{tabular}

cables was of $0.586 \mathrm{~m}$. The geometric characteristics of the bridge considered in this work were the follow (Table 3).

\section{Live loads applied}

The liveloads considered were again the ones present in the original design report provided by RSA (1983), in which two types of live loads are considered (Table 4).

\section{Computer modelling of the structure}

The fully 3D computer model of the structure was made in the software (SAP 2000). It was also made a geometrical non-linear analysis, but it was considered a material linear analysis. This last approximation is realistic, since during the design phase, none of the stresses presented in the structure are above the yield stress at the time. According to observed "in situ" and what was reported in (Steinman 1960) the girder is supported in both towers.

Two types of finite elements were used: the 1st was the enhanced cable element for the cable; the 2nd was the frame element for the bridge girder and the hangers. The cross section of the frame elements used in the truss of the
Fig. 16 Sections of the deck girder. a Diagonal and vertical struts of the girder, b horizontal upper and bottom struts/ties of the girder cross section (a)

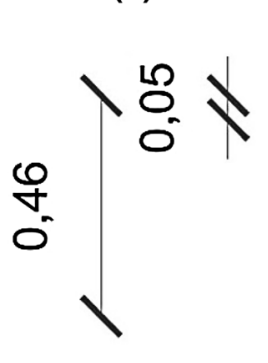

(b)

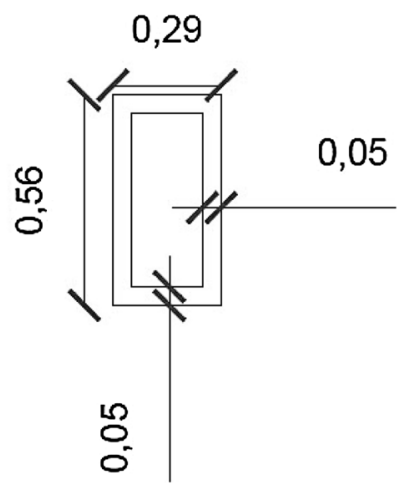


Table 3 Geometry of the structure

\begin{tabular}{lccl}
\hline Midspan $(\mathrm{m})$ & Sidespan $(\mathrm{m})$ & Cable sag $(\mathrm{m})$ & Girder span $(\mathrm{m})$ \\
\hline 1035 & 469 & 103 & 21 \\
\hline $\begin{array}{l}\text { Hangers } \\
\text { diameter }(\mathrm{m})\end{array}$ & $\begin{array}{l}\text { Cable diameter } \\
(\mathrm{m})\end{array}$ & $\begin{array}{l}\text { Number of } \\
\text { cables }\end{array}$ & $\begin{array}{l}\text { Girder inertia } \\
\left(\mathrm{m}^{4}\right)\end{array}$ \\
\hline 0.064 & 0.586 & 2 & 34,117 \\
\hline
\end{tabular}

Table 4 Loads to be applied in the proposed model

\begin{tabular}{ll}
\hline Uniform load $(\mathrm{kN} / \mathrm{m})$ & Point load $(\mathrm{kN})$ \\
\hline 84 & 1050 \\
\hline
\end{tabular}

girder are presented in Fig. 16. It was limited the maximum size of all finite elements of $1.0 \mathrm{~m}$.

It is important to point out that this model presented an extra flexibility when compared with the proposed method, namely the vertical and horizontal deformation of the towers. These even though small contribute to decrease the level of axial tension in the cables.

The loads were considered to be applied in the span and it was obtained the resulting bending moment (using the tool "section cut" of SAP2000 in the girder) at the midspan and the cables horizontal tension stress (Fig. 17).

\section{Obtained values}

Next the outputs of the cable tension and bending moment of the proposed method and the finite element model are presented in Table 5, in which it is possible to observer a general error below $4.3 \%$, which leads to the conclusion that even on a 3D model with geometrical non-linear analysis and tower flexibility, the proposed method possesses extraordinary results for the pre-design phase. A small point that it is important to notice is that the proposed method does not guarantee an upper or lower bond of the resulting forces.
Table 5 Relative error obtained when compared the proposed method to the computer analysis

\begin{tabular}{lll}
\hline$H_{\text {proposed method }}(\mathrm{kN})$ & $H_{\text {SAP2000 }}(\mathrm{kN})$ & Relative error $(\%)$ \\
\hline $107,980.67$ & $105,408.65$ & 2.44 \\
\hline$M_{\text {proposed method }}(\mathrm{kNm})$ & $M_{\text {SAP2000 }}(\mathrm{kNm})$ & Relative error $(\%)$ \\
\hline $125,853.41$ & $131,402.3$ & 4.22 \\
\hline
\end{tabular}

\section{Conclusions}

After the analysis of the proposed method several conclusions can be obtained, using the results and observations from the parametric tests and real case study.

- The proposed method for uniform live load provides excellent results for the preliminary design phase with errors below $10 \%$ in terms of stress prediction. The main errors belong to spans lengths that are not used in cable suspension bridges, this happens due to the exchange of the initial cable shape resulted from high deformation. Therefore, concluding that this method is precise for general geometries.

- The proposed method for the point load provides a good technique although with errors around an average of $20 \%$, almost the double of the uniform load. In any case it is still a good methodology for the pre-design phase to estimate general cable shape and girder cross section. This is also not a problem in cable suspension bridges since the stress caused by the point load is generally $1 / 10$ of the stress caused by the uniform load.

- In both methods it was observed that none of them provide an upper or lower bound for the cable tension and bending moment. This is important since it is necessary for the bridge designer to know that the estimated values do not provide any "extra" structural safety.

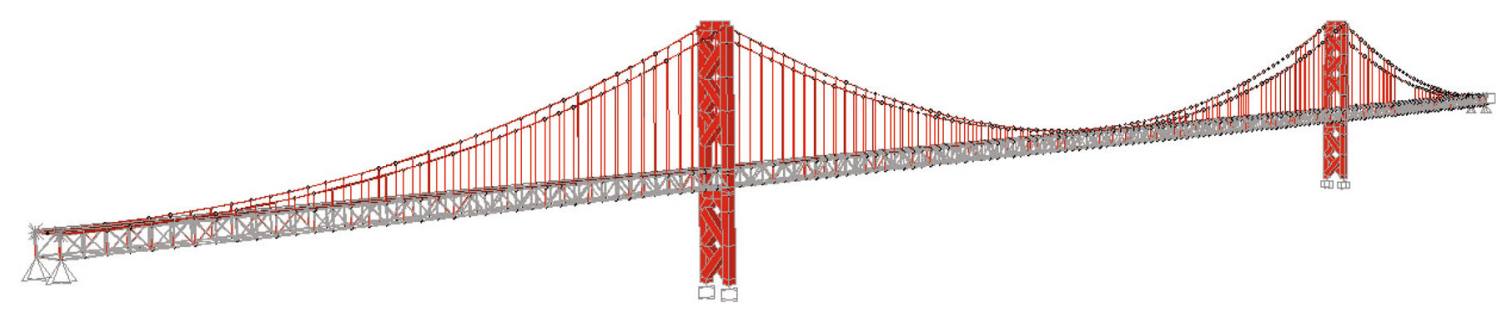

Fig. 17 Computer model of the Tagus bridge made in SAP2000 
Acknowledgements The first author thanks the Portuguese National Science Foundation (FCT) for his Post-Doc scholarship SFRH/BPD/ 99902/2014

Open Access This article is distributed under the terms of the Creative Commons Attribution 4.0 International License (http://crea tivecommons.org/licenses/by/4.0/), which permits unrestricted use, distribution, and reproduction in any medium, provided you give appropriate credit to the original author(s) and the source, provide a link to the Creative Commons license, and indicate if changes were made.

\section{References}

Ahmadi-Kashani K (1983) Development of cable elements and their applications in the analysis of cable structures, $\mathrm{PhD}$ thesis. University of Manchester Institute of Science and Technology (UMIST)

Belytschko T, Fish J (2007) A first course in finite elements. John Wiley and Sons Inc, Hoboken

Bowles JE (1995) Foundation analysis and design. McGraw-Hill Science, New York

Branco FA (1994) Viaduto de Alcântara de ponte 25 de Abril. CMEST, Instituto Superior Técnico CEris, Lisbon

Brockenbrough RL, Merritt FS (1999) Structural steel designer's handbook. McGraw-Hill, New York

Chen W-F, Duan L (2014) Bridge engineering handbook: construction and maintenance. CRC Press, Boca Raton

Crisfield MA (1991) Non-linear finite element analysis of solids and structures, vol. 1. Essentials. Wiley, Chichester

Crisfield MA (1997) Non-linear finite element analysis of solids and structures, vol. 2. Advanced topics, Wiley, Chichester

Drewry CS (1832) A memoir of suspension bridges: comprising the history of their origin and.... BiblioBazar, Charleston

Ghali A, Nevillle AM (1997) Structural analysis: a unified classic and matrix approach. E \& FN Spon, London

Gimsing NJ, Georgakis CT (2011) Cable supported bridges: concept and design. Wiley, Hoboken

Hetenyi M (1971) Beams on elastic foundation: theory with applications in the fields of civil and mechanical engineering. University of Michigan, Ann Arbor
Holger S (2013) Cable-stayed Bridges: 40 years of experience worldwide. Wiley, Hoboken

Inglis CE (1963) Applied mechanics for engineers. Dover, New York Irvine HM (1981) Cable structures. MIT Press, Cambridge

Jennings A (1987) Deflection theory analysis of different cable profiles for suspension bridges. Eng Struct 9(2):84-94

Leonhardt F (1979) Construções de Concrete Armado: Principios Básicos da Construção de Pontes de Concreto, 6. Editora Interciencia LTDA, Rio de Janeiro

LUSOPONTE (2000) Projecto de Expansão e Beneficiação da Ponte 25 de Abril. Lisbon. http://www.lusoponte.pt/

Martha LF (2009) Análise de Estruturas. Elsevier, Rio de Janeiro

Melan J (1913) Theory of arches and suspension bridges. Clark Publishing Company, Palm Beach

Menn C (1990) Prestressed concrete bridges. Springer, Wien

Parke G, Hewson N (2000) ICE manual of bridge engineering. ICE manuals, Thomas Telford Ltd, Scotland

RSA (1983) Regulamento de Seguranças e Acções para Estruturas de Edifícios e Pontes. Ministerio das Obras Publicas, Lisboa

SAP (2000). Structural analysis program. CSI. Computers and Structures Incorporated, Berkeley. http://www.csiberkeley.com/

Serafim JPM (2014) Métodos Simplificados para o Pré-Dimensionamento de Pontes Suspensas, MSc. Departamento de Engenharia Civil, Universidade Nova de Lisboa

Steinman DB (1960) Desgin of the Salazar Bridge. US Steel, Lisbon

Tadaki K (2010) History of the modern suspension bridge: solving the dilemma between economy and stiffness. ASCE Press, New York

Tibert G (1999) Numerical analyses of cable roff structures, Lic Degree. KTH Superseded Departments, Structural Engineering, Stockholm

Timoshenko SP, Young DH (1965) Theory of Structures. McGrawHill, New York

Von-Karman T, Biot MA (1940) Mathematical methods in engineering; an introduction to the mathematical treatment of engineering problems, McGraw-Hill, New York

West HH, Robinson AR (1967) Re-examination of the theory of suspension bridges. C. E., Civil Engineering Department, University of Illinois Press, Champaign

Wilson E (2002) 3D static and dynamic analysis of structures. Computers and Structures, Berkeley 